\title{
Measurement Uncertainty in Testing of Uniaxial Compressive Strength and Deformability of Rock Samples
}

\author{
D. Kuhinek, I. Zorić, P. Hrženjak \\ Faculty of Mining, Geology and Petroleum Engineering, University of Zagreb, Pierottijeva, 6, HR-10002, Zagreb, Croatia, \\ dalibor.kuhinek@rgn.hr, igor.zoric@rgn.hr, petar.hrzenjak@rgn.hr \\ This paper describes instrumental measurement uncertainties and their influence on the result obtained from determination of \\ rock sample uniaxial compressive strength and deformability. The interdependence of uncertainty contribution is analyzed and \\ guides for improving measurement uncertainty are given. The achieved uncertainties are compared to typical uncertainties in the \\ determination of concrete and metallic material compressive strength and deformability.
}

Keywords: uniaxial compressive strength, deformability, rock samples, uncertainty

\section{INTRODUCTION}

$\mathrm{O}$ NE of the basic and most used methods of testing which is performed on rock samples is determination of uniaxial compressive strength and deformability. The testing method is proposed by the International Society for Rock Mechanics [1] in the form of Suggested Method and based on the guidelines in this document, some national standards were derived. Subsequently, additional documents [2] have been published that describe requirements and difficulties that arise from implementation of testing in detail and methods to overcome these difficulties. The latest literature dealing with determination of rock sample properties [3] has replaced [4] and [5]. Reference [3] is extended standard test method which also includes confined testing in various temperatures when compared to [2].

Similar testing is performed on other types of materials like concrete [6] and metals [7] - [9] with some differences in testing procedures and minimum measurement equipment properties. Testing of concrete sample properties has the most similarities with the testing of rock samples. The metals are tested for tensile strength as opposed to rock and concrete. Homogeneity of metallic materials is better than in concrete samples. Also, homogeneity of concrete samples is usually better than in rock samples. Homogeneity is important because it influences repeatability of measurement.

According to the method [2], a rock sample of $54 \mathrm{~mm}$ in diameter and height from 2.5 to 3 times higher than its diameter is placed in the compression test machine and compressive force is applied to the sample. The force should have constant increase over time until the sample breaks and is disintegrated while simultaneously axial and lateral deformations are measured. The result is uniaxial compressive strength, i.e., stress at which the sample is disintegrated. If axial deformations are measured, Young's modulus of elasticity can be obtained. If lateral deformations are measured, the sample's Poisson's coefficient is also obtained.

A large difficulty in implementing the presented measurements is sample nonhomogeneity. Therefore, repeated measurements in equal conditions using different samples will give a variation in measurement results caused by material structure, i.e., nonuniform grain size, arrangement and micro cracks. It is not unusual that this variation is in the range of more than a few percent, i.e., $20 \%$ [10]. Therefore, at least five samples are tested and the results are averaged to represent the properties of the material from which the samples are obtained. It is suggested that test results from samples which substantially deviate from the average are not used for calculating the final result. Rock samples can have uniaxial strength in the range from $5 \mathrm{MPa}$ for soft rock, up to $250 \mathrm{MPa}$ for very brittle rock. Concurrently, Young's modulus of elasticity is in the range from $5 \mathrm{GPa}$ to $120 \mathrm{GPa}$. Poisson's ratio is mostly in the range from 0.1 to 0.45 .

\section{MEASUREMENT MODEL AND EQUIPMENT PROPERTIES}

The first quantity that is indirectly determined by the measurement is uniaxial compressive strength which depends on the force applied to the sample. The second quantity is Young's modulus of elasticity which depends on force and sample axial deformation. The third quantity is Poisson's ratio of material.

\subsection{Uniaxial compressive strength}

Sample stress $\sigma$ is calculated as the ratio of compressive force $F$ and sample cross-section area $A$ at the beginning of the test according to (1) and uniaxial compressive strength as the ratio of maximum applied force $F_{\max }$ and crosssection area $A$.

$$
\sigma=\frac{F}{A}
$$

Therefore, the measurement uncertainty of stress is dependant on the uncertainty of force and the uncertainty of area. Experience has shown that the compression test machine (CTM) has to have very high stiffness, which is smaller if load cell is used and placed on top of the sample [2]. The ideal load cell should have small stiffness to achieve good quality measurements. Therefore, pressure transducer is used to measure oil pressure in the machine and force is calculated as the product of machine pressure 
and cross-section area of cylinder $A_{\mathrm{M}}$ that compresses the sample:

$$
F=p \cdot A_{\mathrm{M}}
$$

which leads to (3):

$$
\sigma=p \frac{d_{\mathrm{M}}^{2}}{d_{0}^{2}}
$$

where $d_{\mathrm{M}}$ is compression test machine cylinder diameter and $d_{0}$ sample diameter.

Although this principle of force measurement gives larger uncertainty, it can give better results in the measurement of rock sample properties.

The pressure is measured using a transducer with the range of 700 bar and accuracy of $\pm 0.2 \%$. Hence, the measured pressure accuracy is equal to \pm 1.4 bar which was used for calculation of uncertainty. During calibration it is established that transducer properties are within limits of \pm 1.2 bar for range of 0 bar to 700 bar and within \pm 0.6 bar for the range of 0 bar to 450 bar which can be achieved by current CTM.

The sample dimensions are measured using vernier caliper with accuracy of $\pm 0.02 \mathrm{~mm}$ and resolution of $0.02 \mathrm{~mm}$.

The compression test machine has cylinder of 8 inch (203.2 mm) in diameter.

Displacement can be measured by using extensometers with an accuracy of $1 \%$ of the reading and precision of $0.2 \%$ of full scale, or LVDTs which should be accurate to $\pm 2 \mu \mathrm{m}[2]$. In the practical example, specification of LVDT is used because LVDTs are currently used in the measurement.

\subsection{Young's modulus of elasticity}

Young's modulus of elasticity $E$ is defined as (4), i.e., the slope of curve obtained in the diagram of axial deformations $\varepsilon$ ( $x$ axis) and stress $\sigma$ ( $y$ axis). The slope is determined in the linear part of the obtained curve which has nonlinearities in the beginning and at the end of the test, caused by rock structure. In the beginning, the cracks are closed and at the end of the test, the material becomes plastic. The modulus can be determined in three ways: tangent, average and secant [2] as presented in Fig.1.
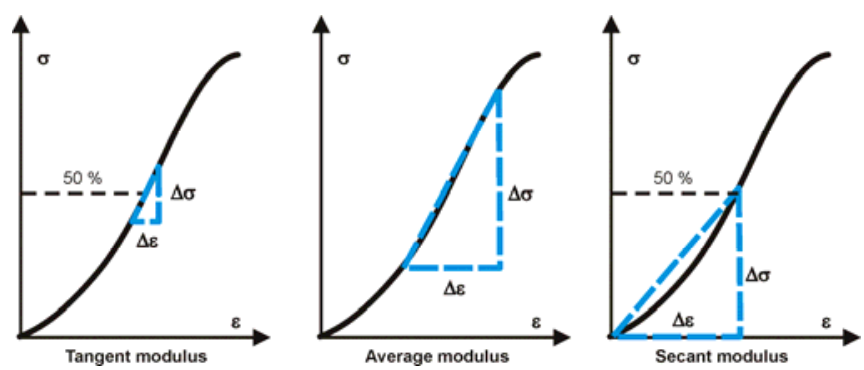

Fig.1. Uncertainties in measurement of sample diameter [2]

$$
E=\frac{\sigma}{\varepsilon}
$$

Deformation is defined as the ratio of change in sample height and height of the sample at the beginning of the test. Since lower and upper plane of the sample is not perfectly flat, a displacement transducer is mounted on the sample and it spans over only a part of the sample height. If the transducer were mounted between the CTM cylinder and the lower plate on which the sample is placed, contact deformations would give deformations which can be higher then sample deformation and that would lead to a bad result. Therefore, transducer span is measured as starting dimension $l_{0}$ and transducer displacement $\Delta l$.

If (3) is placed in (4), using previously defined deformation, follows (5).

$$
E=p \frac{l_{0}}{\Delta l} \frac{d_{\mathrm{M}}^{2}}{d_{0}^{2}}
$$

\subsection{Poisson's coefficient}

Poisson's coefficient $v$ is defined [11] as (6), where $\varepsilon_{\mathrm{a}}$ is axial deformation and $\varepsilon_{\mathrm{d}}$ is lateral deformation. It can be also written as (7).

$$
\begin{gathered}
v=-\frac{\varepsilon_{\mathrm{d}}}{\varepsilon_{\mathrm{a}}} \\
v=-\frac{E}{\text { slope of lateral curve }}
\end{gathered}
$$

Lateral deformation is defined as the ratio of change in sample diameter $\Delta d$ and diameter $d_{0}$ of the sample at the beginning of the test. From (6) follows (8).

$$
v=\frac{\Delta d \cdot l_{0}}{\Delta l \cdot d_{0}}
$$

\section{RESUlts}

\subsection{Uncertainty of sample dimensions}

The diameter of the test specimen shall be measured to the nearest $0.1 \mathrm{~mm}$ by averaging two diameters measured at right angles to each other close to the top, the mid-height and the bottom of the specimen. The average diameter shall be used for calculating the cross-sectional area. The height of the specimen shall be determined to the nearest $1.0 \mathrm{~mm}$ $[2]$.

This means that there are six diameter measurements, which are averaged and then the result is rounded. The first contribution to the uncertainty is standard deviation $s$ of the measurement and standard uncertainty (9) is calculated according to [12] and [13], depending on the number of measurements $n$. This is A type contribution. Other contributions are resolution of caliper, flatness and parallelism of each face, squareness error and calibration error given in calibration certificate. These are B type contributions. For variables with rectangular distribution, uncertainty of B type is calculated by dividing the half width interval with square root of number 3 . Uncertainty from 
resolution and rounding is obtained by dividing the resolution by factor two and then with square root of three, i.e., full interval is divided by square root of 12 [14], [15].

$$
u\left(d_{0}\right)=\sqrt{\frac{n-1}{n-3}} \frac{s\left(d_{0}\right)}{\sqrt{n}}
$$

\subsection{Uncertainty of measured pressure}

The pressure measurement uncertainty is obtained by dividing transducer error specification with square root of 3 because this contribution has rectangular distribution.

\subsection{Uniaxial strength uncertainty}

Combined standard uncertainty $u_{\mathrm{C}}(\sigma)$ is calculated in (10) according to GUM [14]. Under the assumption that dimension measurements are not correlated, follows (11) for uniaxial strength defined by measurement model (3):

$$
\begin{aligned}
& u_{\mathrm{C}}^{2}(\sigma)=\sum_{i=1}^{n}\left(\frac{\partial \sigma}{\partial x_{i}}\right)^{2} u^{2}\left(x_{i}\right) \\
& u_{\mathrm{C}}^{2}(\sigma)=\left(\frac{d_{\mathrm{M}}^{2}}{d_{0}^{2}}\right)^{2} u^{2}(p)+\left(\frac{2 p d_{\mathrm{M}}}{d_{0}^{2}}\right)^{2} u^{2}\left(d_{\mathrm{M}}\right) \\
& +\left(\frac{2 p d_{\mathrm{M}}^{2}}{d_{0}^{3}}\right)^{2} u^{2}\left(d_{0}\right) \\
& u_{\mathrm{C}}^{2}(v)=\sum_{i=1}^{n}\left(\frac{\partial v}{\partial x_{i}}\right)^{2} u^{2}\left(x_{i}\right) \\
& u_{\mathrm{C}}^{2}(E)=\left(\frac{l_{0}}{\Delta l} \frac{d_{\mathrm{M}}^{2}}{d_{0}^{2}}\right)^{2} u^{2}(p)+\left(\frac{p}{\Delta l} \frac{d_{\mathrm{M}}^{2}}{d_{0}^{2}}\right)^{2} u^{2}\left(l_{0}\right)+\left(\frac{2 \cdot p \cdot l_{0}}{\Delta l} \frac{d_{\mathrm{M}}}{d_{0}^{2}}\right)^{2} u^{2}\left(d_{\mathrm{M}}\right)+\left(\frac{-2 \cdot p \cdot l_{0}}{\Delta l} \frac{d_{\mathrm{M}}^{2}}{d_{0}^{3}}\right)^{2} u^{2}\left(d_{0}\right) \\
& +\left(\frac{-p \cdot l_{0}}{\Delta l^{2}} \frac{d_{\mathrm{M}}^{2}}{d_{0}^{2}}\right)^{2} u^{2}(\Delta l) \\
& u_{\mathrm{C}}^{2}(v)=\left(\frac{\Delta d}{d_{0} \cdot \Delta l}\right)^{2} u^{2}\left(l_{0}\right)+\left(-\frac{l_{0} \cdot \Delta d}{d_{0} \cdot \Delta l^{2}}\right)^{2} u^{2}(\Delta l)+\left(-\frac{l_{0} \cdot \Delta d}{d_{0}^{2} \cdot \Delta l}\right)^{2} u^{2}\left(d_{0}\right)+\left(\frac{l_{0}}{d_{0} \cdot \Delta l}\right)^{2} u^{2}(\Delta d)
\end{aligned}
$$

\subsection{Young's modulus uncertainty} easier to notice possible correlation of input quantities. (5):

$$
u_{\mathrm{C}}^{2}(E)=\sum_{i=1}^{n}\left(\frac{\partial E}{\partial x_{i}}\right)^{2} u^{2}\left(x_{i}\right)
$$

\subsection{Poisson's coefficient}

Under the assumption that secant elasticity modulus is determined, (4) or (5) can be used. Relation (5) is used in the following example because all uncertainty contributions of modulus can be compared. Also, in this manner it is

The combined standard uncertainty $u_{\mathrm{C}}(E)$ is calculated in (12) according to GUM [14]. Again, under the assumption that dimension measurements are not correlated, follows (13) for Young's modulus defined by measurement model

Combined standard uncertainty $u_{\mathrm{C}}(v)$ is calculated in (14) according to GUM [14]. Again, under the assumption that dimension measurements and displacement are not correlated, follows (15) for Poisson's coefficient defined by

\section{Practical EXAMPLE}

For a clearer understanding, the following example is

\begin{tabular}{|c|c|c|c|c|c|}
\hline Quantity & Estimate & $\begin{array}{l}\text { Standard } \\
\text { uncertainty }\end{array}$ & $\begin{array}{l}\text { Probabillity } \\
\text { distribution }\end{array}$ & $\begin{array}{l}\text { Sensitivity } \\
\text { coefficient }\end{array}$ & $\begin{array}{l}\text { Uncertainty } \\
\text { contribution } \\
(\mathrm{mm})\end{array}$ \\
\hline St. deviation & $0.0234 \mathrm{~mm}$ & $0.0123 \mathrm{~mm}$ & \begin{tabular}{|c|} 
students $\mathrm{t}$ \\
\end{tabular} & 1 & 0.0123 \\
\hline Resolution & $0.02 \mathrm{~mm}$ & $0.0058 \mathrm{~mm}$ & rectangular & 1 & 0.0058 \\
\hline Flatness & $0.005 \mathrm{~mm}$ & $0.0029 \mathrm{~mm}$ & rectangular & 1 & 0.0029 \\
\hline Parallelism & $0.008 \mathrm{~mm}$ & $0.0046 \mathrm{~mm}$ & rectanqular & 1 & 0.0046 \\
\hline Calibration & $0.02 \mathrm{~mm}$ & $0.0115 \mathrm{~mm}$ & rectangular & 1 & 0.0115 \\
\hline Rounding & $0.1 \mathrm{~mm}$ & $0.0289 \mathrm{~mm}$ & rectangular & 1 & 0.0289 \\
\hline Sample diameter & $54.163 \mathrm{~mm}$ & & & $u_{\mathrm{C}}\left(d_{0}\right)=$ & 0.034 \\
\hline
\end{tabular}
explained. Typical diameter measurement results are presented in Table 1. All uncertainty contributions are calculated in Table 2 and presented in Fig.2.

Tab.1. Typical measurement of sample diameter.

\begin{tabular}{|c|c|}
\hline Measurement No. & Diameter $(\mathrm{mm})$ \\
\hline 1 & 54.20 \\
\hline 2 & 54.16 \\
\hline 3 & 54.14 \\
\hline 4 & 54.16 \\
\hline 5 & 54.18 \\
\hline 6 & 54.14 \\
\hline
\end{tabular}

From the obtained standard deviation of $0.0234 \mathrm{~mm}$ follows standard uncertainty of $0.0123 \mathrm{~mm}$ as presented in (9). Flatness and parallelism are estimated as in [16].

Tab.2. Combined uncertainty of diameter measurement. 
When uncertainty contributions are compared, it can be concluded that vernier caliper is a satisfactory instrument for sample dimension measurement and dominant contribution comes from rounding the result.

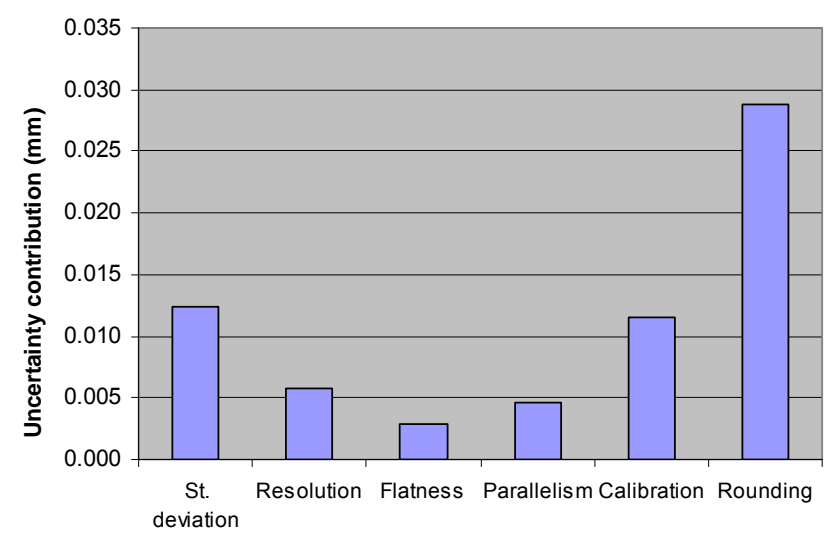

Fig.2. Uncertainties in measurement of sample diameter

Uncertainty of sample height depends even more dominantly on rounding.

Uniaxial strength uncertainty depends on the uncertainty of pressure and sample diameter before the test. The diameter of CTM cylinder was not measured because it was obtained from manufacturer documentation, but measurement uncertainty was not stated. Under the assumption that uncertainty of CTM diameter is equal to the uncertainty of sample diameter, results given in Table 3 and Fig.4. are obtained. Uncertainty of CTM diameter is surely smaller than assumed, because it is a precisely manufactured machine part made with small tolerances.

Tab.3. Combined uncertainty of uniaxial strength measurement.

\begin{tabular}{|c|c|c|c|c|c|}
\hline Quantity & Estimate & $\begin{array}{l}\text { Standard } \\
\text { uncertainty }\end{array}$ & $\begin{array}{l}\text { Probabillity } \\
\text { distribution }\end{array}$ & $\begin{array}{l}\text { Sensitivity } \\
\text { coefficient }\end{array}$ & $\begin{array}{c}\text { Uncertainty } \\
\text { contribution } \\
\text { (MPa) }\end{array}$ \\
\hline FTres & $\mathrm{MPa}$ & $\mathrm{a}$ & & 14 & 1.136 \\
\hline CTM diam & $2 \mathrm{~mm}$ & $\mathrm{~mm}$ & rect & $2.1330 \mathrm{MP}$ & 0.073 \\
\hline Sample diame & $54.2 \mathrm{~mm}$ & \begin{tabular}{|l|}
$0.0343732 \mathrm{~mm}$ \\
\end{tabular} & rectangular & $-7.9967 \mathrm{MPa} / \mathrm{mm}$ & -0.275 \\
\hline Strength & $216.7 \mathrm{MPa}$ & & & $u_{\mathrm{c}}(\sigma)=$ & 1.2 \\
\hline
\end{tabular}

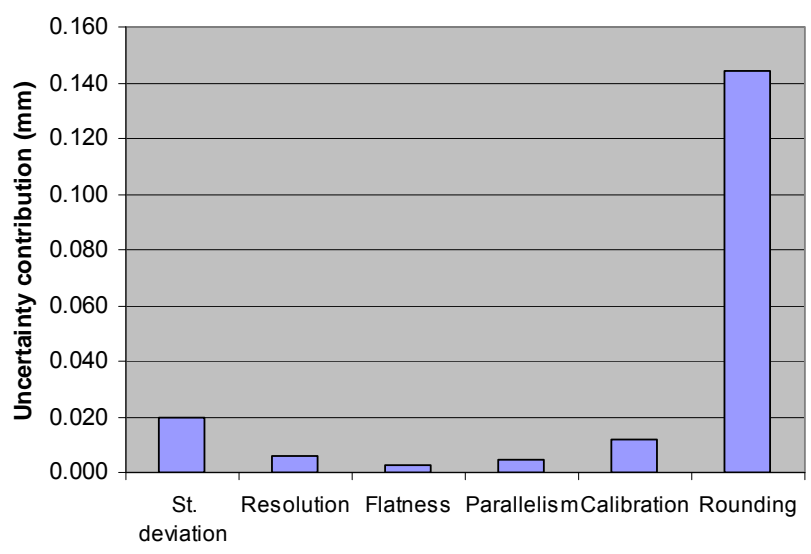

Fig.3. Uncertainties in measurement of sample height
Pressure uncertainty is dominant contribution to the combined standard uncertainty, which means that if pressure transducer with smaller error limits is used, it will lead to decreased uncertainty of compressive strength.

The use of pressure transducer with equal accuracy class and smaller range could be used for samples obtained from softer rock, where smaller strength is expected, which would decrease uncertainty. If pressure uncertainty were halved, the decrease of strength uncertainty would be substantial. Additional reduction has no sense unless sample diameter is measured with smaller uncertainty.

The relative standard uncertainty of strength is lower than $1 \%$ for strength larger than $118 \mathrm{MPa}$.

If secant Young's modulus is determined, pressure and strength used for calculation are at $50 \%$ of maximum value achieved during testing. Calculation presented in Table 4 and Fig.5. follows.

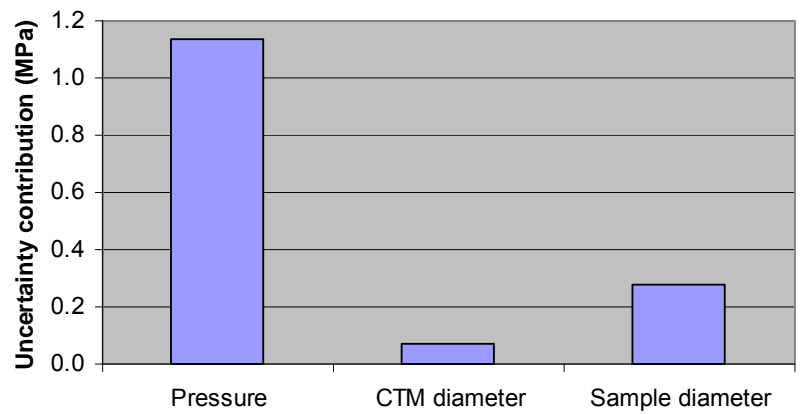

Fig.4. Uncertainties in measurement of uniaxial strength

Under the assumption that dimensional measurements are uncorrelated, follows that uncertainty of elasticity modulus is similarly influenced by pressure uncertainty, sample height uncertainty and displacement uncertainty, because these contributions have similar distribution width. The uncertainty of sample and CTM diameter are smaller than one third of the maximum uncertainty contribution and therefore can be considered negligible.

Using a pressure transducer with lower uncertainty is not sufficient to improve modulus uncertainty. To achieve lower modulus uncertainty, the use of pressure and displacement transducer with lower uncertainty is required. If these uncertainties are halved, combined standard uncertainty will be improved. Additional lowering has sense if height dimension is rounded to a limit smaller than $1 \mathrm{~mm}$.

Tab.4. Combined uncertainty of Young's modulus of elasticity.

\begin{tabular}{|l|c|r|r|r|r|}
\hline \multicolumn{1}{|c|}{ Quantity } & Estimate & $\begin{array}{c}\text { Standard } \\
\text { uncertainty }\end{array}$ & $\begin{array}{l}\text { Probabillity } \\
\text { distribution }\end{array}$ & $\begin{array}{l}\text { Sensitivity } \\
\text { coefficient }\end{array}$ & $\begin{array}{r}\text { Uncertainty } \\
\text { contribution } \\
(\mathrm{GPa})\end{array}$ \\
\hline Pressure & $7.709083 \mathrm{MPa}$ & $0.080829 \mathrm{MPa}$ & rectangular & 7.646 & 0.618 \\
\hline Height & $68 \mathrm{~mm}$ & $0.1463 \mathrm{~mm}$ & rectangular & $0.867 \mathrm{GPa} / \mathrm{mm}$ & 0.127 \\
\hline CTM diameter & $203.2 \mathrm{~mm}$ & $0.0343732 \mathrm{~mm}$ & rectangular & $0.580 \mathrm{GPa} / \mathrm{mm}$ & 0.020 \\
\hline Diameter & $54.2 \mathrm{~mm}$ & $0.0343732 \mathrm{~mm}$ & rectangular & $-2.175 \mathrm{GPa} / \mathrm{mm}$ & -0.075 \\
\hline Displacement & $125 \mu \mathrm{m}$ & $1.154700538 \mu \mathrm{m}$ & rectangular & $-0.472 \mathrm{GPa} / \mu \mathrm{mm}$ & -0.545 \\
\hline Young's modulus & $58.95 \mathrm{GPa}$ & \multicolumn{5}{|r}{} & $u_{\mathrm{C}}(E)=$ & 0.84 \\
\hline
\end{tabular}


The relative standard uncertainty of elasticity modulus is lower than $1 \%$ for elasticity modulus larger than 84 GPa.

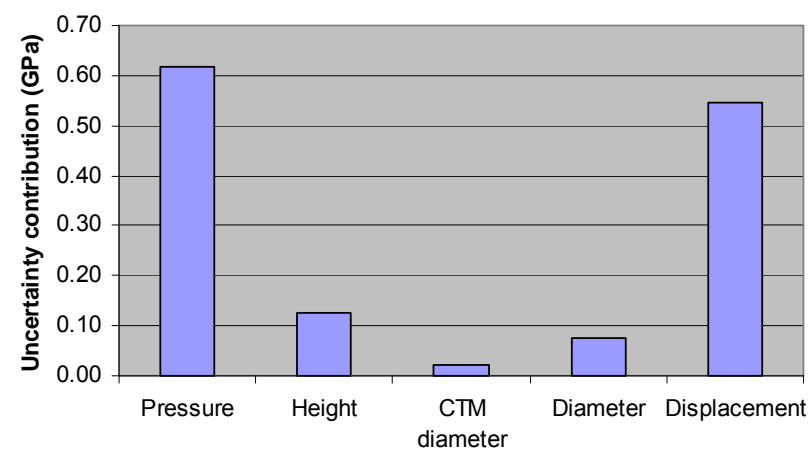

Fig.5. Uncertainties in measurement of modulus of elasticity.

If Poisson's secant coefficient is determined, calculation presented in Table 5 and Fig.6. follows.

Tab.5. Combined uncertainty of Poisson's coefficient.

\begin{tabular}{|c|c|c|c|c|c|}
\hline Quantity & Estimate & $\begin{array}{c}\text { Standard } \\
\text { uncertainty }\end{array}$ & $\begin{array}{l}\text { Probabillity } \\
\text { distribution }\end{array}$ & $\begin{array}{l}\text { Sensitivity } \\
\text { coefficient }\end{array}$ & $\begin{array}{l}\text { Uncertainty } \\
\text { contribution }\end{array}$ \\
\hline Height & $68 \mathrm{~mm}$ & $0.146 \mathrm{~mm}$ & rectangular & $0.00295 \mathrm{~mm}^{-1}$ & 0.00043 \\
\hline Axial displacement & $125 \mu \mathrm{m}$ & $1.15 \mu \mathrm{m}$ & rectangular & $-0.00161 \mu \mathrm{m}^{-1}$ & -0.00185 \\
\hline Sample diameter & $54.2 \mathrm{~mm}$ & $0.0344 \mathrm{~mm}$ & rectangular & $-0.0037 \mathrm{~mm}^{-1}$ & -0.00013 \\
\hline Lateral displacement & $20 \mu \mathrm{m}$ & $1.15 \mu \mathrm{m}$ & rectangular & $0.01004 \mu \mathrm{m}^{-1}$ & 0.01159 \\
\hline Poisson's coefficient & 0.20074 & \multicolumn{4}{|r|}{0.0117} \\
\hline
\end{tabular}

Under the assumption that dimensional measurements and displacements are uncorrelated, follows that Poisson's coefficient uncertainty dominantly influences lateral displacement uncertainty. Other sources of uncertainty are negligible. The use of extensometer with lower error limits instead of LVDT would decrease Poisson's coefficient uncertainty. For example, class 0.2 extensometer has bias error of $\pm 0.6 \mu \mathrm{m}$ [17] which would decrease uncertainty. Strain gauges are an attractive and cost effective alternative to the high resolution extensometer [17].

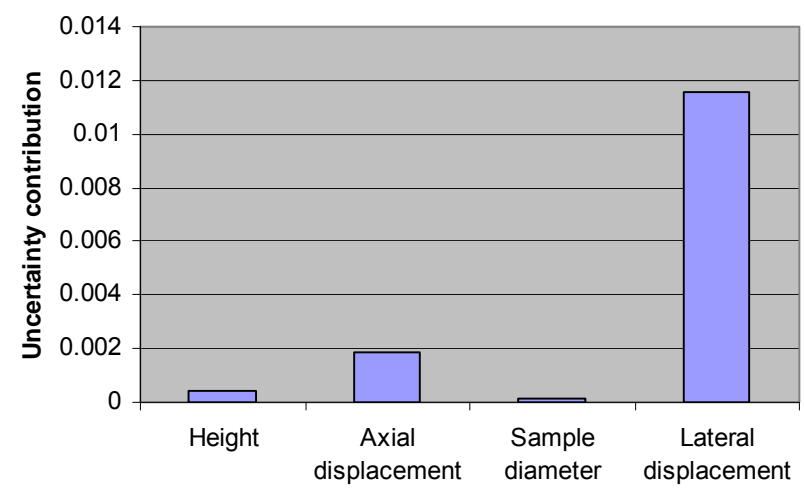

Fig.6. Uncertainties in measurement of Poisson's coefficient.

The relative standard uncertainty of Poisson's coefficient is in the range from $2.6 \%$ to $12 \%$ for expected values.

\section{DISCUSSION}

Dimensional measurements are performed with an identical instrument, which means that sources of uncertainty associated with that instrument should appear more than once in the uncertainty budget, i.e., lead to correlated input quantities. In this case, dominant uncertainties come from rounding, which means that they are not correlated [15], [18]. Hence, the assumption of noncorrelated dimensional measurements is justified.

The results of measurement presented in this paper are used for calculation of intact rock properties. In situ rock mass properties depends on intact rock properties but strongly on structural features. Rock mass properties are then used for example in slope stability, underground excavation etc. Therefore, safety factors mostly in the range from 2 to 10 are used and the achieved uncertainties are satisfactory for this type of application. This does not mean that presented measurements could not or should not be performed with greater quality.

Tab.6. Strength and standard uncertainty in testing of concrete and steel.

\begin{tabular}{|c|c|c|}
\hline & Concrete [19] & Rolled steel [20] \\
\hline$\sigma$ & $33 \mathrm{MPa}$ & $478.6 \mathrm{MPa}$ \\
\hline$u_{\mathrm{C}}(\sigma)$ & $0.1 \mathrm{MPa}$ & $2.9 \mathrm{MPa}$ \\
\hline$u_{\mathrm{C} \%}(\sigma)$ & $0.3 \%$ & $0.6 \%$ \\
\hline
\end{tabular}

Table 6 and Table 7 present uncertainties in the measurement of properties of concrete and metal samples. The obtained uncertainties from the practical example are larger than those presented in Table 6 and Table 7. It should be noted that the presented uncertainty calculation gives information on where and how uncertainties can be lowered, if necessary.

Tab.7. Young's modulus and standard uncertainty in tensile test

\begin{tabular}{|c|c|c|}
\hline & Metal [17] & Cold rolled steel [21] \\
\hline$E$ & $210 \mathrm{GPa}$ & $207.5 \mathrm{GPa}$ \\
\hline$u_{\mathrm{C}}(E)$ & $0.7 \mathrm{GPa}$ & $0.85 \mathrm{GPa}$ \\
\hline$u_{\mathrm{C} \%}(E)$ & $0.33 \%$ & $0.41 \%$ \\
\hline
\end{tabular}

\section{CONCLUSION}

This paper describes contributions to uncertainty of results obtained by testing of rock sample deformability, i.e., those that come from limitations of the used instruments and transducers. Uncertainty contributions are assessed and compared in an example and guidelines for lowering the combined standard uncertainty are given.

The relative standard uncertainty of strength is lower than $1 \%$ for strength larger than $118 \mathrm{MPa}$. The relative standard uncertainty of elasticity modulus is lower than 1 $\%$ for elasticity modulus larger than $84 \mathrm{GPa}$. The relative standard uncertainty of Poisson's coefficient is in the range from $2.6 \%$ to $12 \%$ for expected values.

Uncertainty contribution from repeatability is not considered since it requires repeating the test with sufficient number of homogeneous samples and calculating the contribution. Also, the influence of 
different stress increase and sample centering is not considered.

\section{REFERENCES}

[1] Bieniawski, T. et al. (1979). Suggested methods for determining the uniaxial compressive strength and deformability of rock materials. International Journal of Rock Mechanics and Mining Sciences \& Geomechanics Abstracts, 16 (2), 137-140.

[2] Fairhurst, C.E., Hudson, J.A. (1999). Draft ISRM suggested method for the complete stress-strain curve for intact rock in uniaxial compression. International Society for Rock Mechanics and Mining Sciences, 36, 279-289.

[3] American Society for Testing and Materials. (2010). ASTM D7012 - 10 Standard Test Method for Compressive Strength and Elastic Moduli of Intact Rock Core Specimens Under Varying States of Stress and Temperatures. West Conshohocken, USA.

[4] American Society for Testing and Materials. (2002). ASTM D3148-02 Standard Test Method for Elastic Moduli of Intact Rock Core Specimens in Uniaxial Compression. West Conshohocken, USA.

[5] American Society for Testing and Materials. (2002). ASTM D2938-95 Standard Test Method for Unconfined Compressive Strength of Intact Rock Core Specimens. West Conshohocken, USA.

[6] European Committee for Standardization. (2009). EN 12390-3: Testing Hardened Concrete - Part 3: Compressive Strength of Test Specimens. Brussels, Belgium.

[7] European Committee for Standardization. (2004). EN 10002-1: Metallic Materials - Tensile Testing: I. Method of Test at Ambient Temperature. Brussels, Belgium.

[8] American Society for Testing and Materials. (2008). ASTM E8/E8M-08: Standard Test Methods for Tension Testing of Metallic Materials. West Conshohocken, USA.

[9] International Standardization Organization. (2009). ISO 6892-1: Metallic Materials - Tensile Testing: I. Method of Test at Room Temperature. Geneva, Switzerland.
[10] Jumikis, A.R. (1983). Rock Mechanics, 2 Ed. Trans Tech Publications.

[11] Gercek, H. (2007). Poisson's ratio value for rocks. International Journal of Rock Mechanics and Mining Sciences, 44, 1-13.

[12] Yadav, S., Gupta, V.K., Prakash, O., Bandyopadhyay, A.K. (2005). Evaluation of associated uncertainties in calibration of direct pressure indicating electromechanical devices. Measurement Science Review, 5 (3), 104-114.

[13] Joint Committee for Guides in Metrology. (2006). Evaluation of Measurement Data - Supplement 1 to the "Guide to the Expression of Uncertainty Measurement" - Propagation of Distributions Using Monte Carlo Method, Final Draft. BIPM. Sèvres, France.

[14] International Standardization Organization. (1995). Guide to the Expression of Uncertainty in Measurement. Geneva, Switzerland.

[15] European Co-operation for Accreditation. (1999). EA 4/02 Expression of the Uncertainty of Measurement in Calibration.

[16] Flack, D. (2001). Calipers and Micrometers. In Measurement Good Practice Guide No. 40. Teddington, Middlesex, UK: National Physical Laboratory.

[17] Lord, J.D., Morrell, R.M. (2010). Elastic modulus measurement - obtaining reliable data from the tensile test. Metrologia, 47, S41-S49.

[18] International Atomic Energy Agency. (2008). IAEA-TECDOC-1585 Measurement Uncertainty A Practical Guide for Secondary Standards Dosimetry Laboratories. Wienna, Austria.

[19] Dumanić, E., Sekulić, D. (2001). Measurement uncertainty of test method for concrete cubes tensile strength. In Proceedings of the $18^{\text {th }}$ Metrology Symposium, 8-10 October 2001. Cavtat, Croatia, 138-141.

[20] Bahn, G.W., Kim, J.J., Lee, H.M., Huh, Y.H. (2010). Establishment of traceability in the measurement of the mechanical properties of materials. Metrologia, 47, S32-S40.

[21] Gabauer, W. (2000). UNCERT Code of Practice 07: The Determination of Uncertainties in Tensile Testing. Linz, Austria. 